\title{
Rare Shunt Complication: Scalp Cerebrospinal Fluid Leakage from Shunt Valve Separation
}

\author{
Seung Hyun Kim, Yong Cheol Lim, Soo Han Yoon \\ Department of Neurosurgery, Ajou University Hospital, Ajou University School of Medicine, Suwon, Republic of Korea \\ Corresponding author: Soo Han Yoon \\ Department of Neurosurgery, Ajou \\ University Hospital, Ajou University \\ School of Medicine, 164, World \\ Cup-ro, Yeongtong-gu, Suwon 16499 \\ Republic of Korea \\ Tel: +82-31-219-5233 \\ Fax: $+82-31-219-5238$ \\ E-mail: ee80@hanmail.net \\ Received: August 30, 2020
}

Revised: September 10, 2020

Accepted: September 11, 2020

\section{INTRODUCTION}

Although cerebrospinal fluid (CSF) shunting has been main treatment modality for hydrocephalic children since the first shunt operation about 70 years ago, shunting is associated with various complications requiring shunt revisions throughout a patient's lifetime ${ }^{5)}$. The most common causes of shunt malfunction were proximal (27\%) and distal (15\%) catheter occlusion, disconnection (11\%), and infection (9\%) ${ }^{12)}$. Ventriculoperitoneal shunt failure rates have been estimated at approximately $11 \%$ to $25 \%$ within the first year after initial shunt operation, with most sources reporting a significantly higher number (4-fold) of shunt revisions and replacements among pediatric patients compared to adults ${ }^{7,8)}$. Here, we report a very rare non-traumatic shunt complication; the valve rupture with small separation between the base and housing of the shunt valve.

\section{CASE REPORT}

The 7-year-old girl visited the neurosurgical outpatient department with the chief complaint of a $2 \mathrm{~cm}$ diameter scalp mass around the shunt valve. She had a history of ventriculoperitoneal shunting with a Medtronic Strata adjustable valve at 6 months old due to hydrocephalus that resulted from postpartum intraventricular hemorrhage. After the shunt operation, the patient had no shunt-related problems until she was found with a scalp mass days before. We observed that she had a
2 diameter soft non-tender subcutaneous occipital scalp mass around the shunt valve that was suspected to be the CSF collection leaking from the shunt system. She underwent simple skull X-rays and computed tomography scan, which showed the intact shunt catheter and shunt valve, and a fluid collection around the shunt valve. We suspected a small breakage invisible on simple X-rays in the shunt catheter or shunt valve caused the CSF leakage. She was subject to a shunt revision: in the operation field, we found that there was no abnormality in the shunt catheter, but small CSF leakage from a $3 \mathrm{~mm}$ length separation between the base and housing of the shunt valve reservoir portion. We replaced the old shunt valve with a new Medtronic Strata adjustable valve. The operation was uneventful and successful. After the operation, we filled the valve with a betadine solution to check for leaks that had showed small leakage from the separation between the base and housing of the shunt valve reservoir portion (Fig. 1). The scalp subcutaneous CSF collection disappeared after the operation. At 6 months follow-up after the valve replacement surgery, she has no complications observed in the outpatient department.

\section{DISCUSSION}

Ventricular peritoneal shunting for hydrocephalus has been established as a CSF conversion procedure, but there are complications, which often occur in more children than adults. McGirt et al. ${ }^{5)}$ analyzed 353 patients who underwent ventriculoperitoneal shunt surgery at the Duke University Medical Center during 1992 to 1998. They found that the most common 


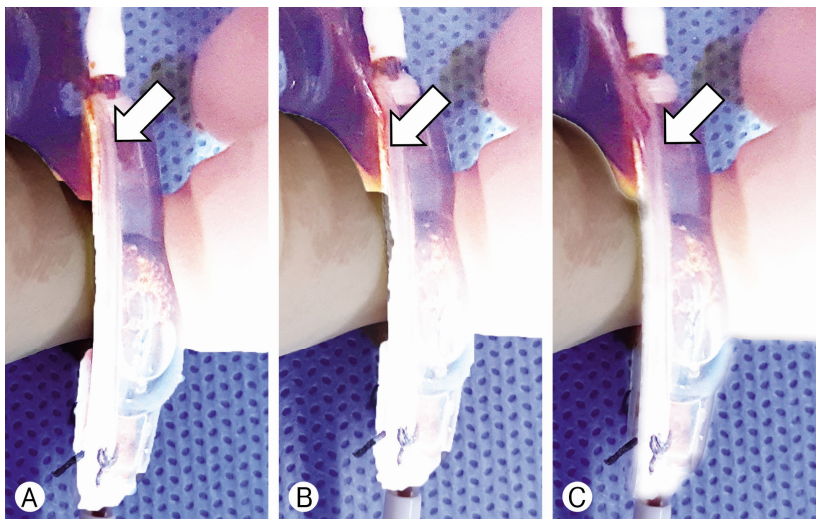

Fig. 1. Separation between base and housing of shunt valve. The valve was filled with betadine solution to check for leaks. Pressing the reservoir to check for betadine solution leakage in the valve break area (arrows).

causes of shunt failure in pediatric and adult populations are shunt obstructions followed by infection, with infections tending to cause early shunt failures and catheter occlusion, typically accounting for late shunt failures. Similarly, Reddy et al. ${ }^{8)}$ found a greater incidence of shunt malfunction among the pediatric population, the shunt revision rate in pediatric patients was $78.7 \%$ (240 of 305 patients) and in adult patients was $32.4 \%$ (230 of 710 patients), which was 4.22 -fold higher than that of adult revision operations.

The most common causes of mechanical shunt failures include fracture, disconnection, and migration. Firstly, for the mechanical shunt fracture, the typical presentation usually appears several years after the initial shunt operation and is related to biomechanical stress as the subject grows and the inherent degradation of indwelling components because of host reactions. Erol et al. ${ }^{1)}$ analyzed patients with ventriculoperitoneal shunt malfunction for 10 years that revealed fractured shunts occurring in $5.5 \%$ of patients requiring revision surgery. They found that the surrounding of the fractured shunts had developed calcifications and a proteinaceous covering with scar formation along the track. The stretching of the catheter can develop a shunt fracture in a growing child especially in the cervical region. The silastic shunt material also causes hypersensitivity and tissue reaction that may form the basis for the fracture.

Secondly, the shunt disconnection was reported to occur in $2.6 \%$ of patients requiring revision surgery. In pediatric patients, shunt disconnection is most frequently observed from rapid growth that may explain why the distal shunt catheter is more frequently disconnected than the proximal shunt catheter ${ }^{1)}$.

Third, shunt migration is reported to occur in 1/1,000 cases of shunt surgery, which can cause shunt malfunction ${ }^{2)}$. This phenomenon can occur with both the proximal catheter, which withdraws from the ventricle, and the distal catheter, which withdraws from the peritoneum. Harischandra et al. ${ }^{3)}$ reported a shunt migration of 396 patients through a literature search. The migration site was intracranial (7.58\%), subgaleal (3.03\%), chest wall/thorax (8.08\%), breast (3.28\%), cardiac/intravascular (7.07\%), abdominal wall (14.39\%), genitourinary (17.68\%), bowel (35.10\%), and miscellaneous (3.79\%).

Except for the above, the most common 3 causes of shunt failures, one of the rare but possible causes is valve breakage. All valve breakage reported in the literature were shunt valve pressure control slator dislodgements: 4 case reports for 9 patients and one analysis paper for 15 . Mauer and Kunz ${ }^{4)}$ reported almost 3\% shunt valve pressure control slator dislodgement from 546 shunt valve revisions of the Codman Hakim ${ }^{\circledR}$ Programmable valve (Codman, Johnson \& Johnson, Raynham, MA, USA) between 1994 and 2010. They explained the cause of shunt valve pressure control slator dislodgement by valve mechanism ages or multiple minor traumas. Schwarm et al. ${ }^{10)}$ reported 5 cases of valve breakages after minor trauma from the 85 children with Codman Hakim ${ }^{\circledR}$ Programmable valve. Shimizu et al. ${ }^{11)}$ and Sato et al. ${ }^{9)}$ respectively reported a 6 year-old girl and a 7 year-old girl with shunt valve pressure control slators dislodgement after minor trauma, while Okazaki et al. ${ }^{\text {) }}$ presented the case of a 7 year-old boy with shunt valve pressure control slator dislodgement following a blow to the head.

In the previous papers, all shunt valve pressure control slator dislodgements occurred in the Codman Hakim ${ }^{\circledR}$ Programmable valve and were mostly caused by minor trauma. In our case, valve breakage was not a shunt valve pressure control slator dislodgement but valve rupture with small gap from the separation between the housing and base of the shunt valve reservoir portion in a Medtronic Strata adjustable valve and with no minor trauma. Perhaps, reservoir pumping and aging may be suspected to be the cause, the solution is to gently perform reservoir pumping, and manufacturers will have to upgrade the quality of the valves. If shunt disconnection or breakage is suspected from CSF leak and collection around shunt system is present, catheter disconnection can be easily found in the operating filed, but not after valve breakage. The authors suggest that the neurosurgeon in charge should check for the presence of valve breakage very carefully if there is no catheter disconnection.

\section{CONCLUSION}

We report a very rare shunt complication of valve rupture with a small separation between the base and housing of the shunt valve. The authors suggest that in the event of CSF leakage, the valve breakage should be also checked carefully if there is no catheter separation.

\section{CONFLICTS OF INTEREST}

No potential conflict of interest relevant to this article was reported. 


\section{REFERENCES}

1. Erol FS, Ozturk S, Akgun B, Kaplan M: Ventriculoperitoneal shunt malfunction caused by fractures and disconnections over 10 years of follow-up. Childs Nerv Syst 33:475-481, 2017

2. Gupta PK, Dev EJ, Lad SD: Total migration of a ventriculo-peritoneal shunt into the ventricles. Br J Neurosurg 13:73-74, 1999

3. Harischandra LS, Sharma A, Chatterjee S: Shunt migration in ventriculoperitoneal shunting: A comprehensive review of literature. Neurol India 67:85-99, 2019

4. Mauer UM, Kunz U: More malfunctioning Medos Hakim programmable valves: cause for concern? J Neurosurg 115:10471052, 2011

5. McGirt MJ, Leveque JC, Wellons JC, $3^{\text {rd }}$, Villavicencio AT, Hopkins JS, Fuchs HE, et al.: Cerebrospinal fluid shunt survival and etiology of failures: A seven-year institutional experience. Pediatr Neurosurg 36:248-255, 2002

6. Okazaki T, Oki S, Migita K, Kurisu K: A rare case of shunt malfunction attributable to a broken Codman-Hakim programmable shunt valve after a blow to the head. Pediatr Neurosurg
41:241-243, 2005

7. Paff M, Alexandru-Abrams D, Muhonen M, Loudon W: Ventriculoperitoneal shunt complications: A review. Interdiscip Neurosurg 13:66-70, 2018

8. Reddy GK, Bollam P, Caldito G: Long-term outcomes of ventriculoperitoneal shunt surgery in patients with hydrocephalus. World Neurosurg 81:404-410, 2014

9. Sato K, Shimizu S, Utsuki S, Suzuki S, Oka H, Fujii K: Disparity between adjusted and actual opening cerebrospinal fluid pressure in a patient with the Codman Hakim programmable valve: occult form of shunt failure due to head banging. Case report. J Neurosurg 105:425-427, 2006

10. Schwarm FP, Nagl J, Bender M, Stein M, Giese K, Hahn A, et al.: Programmable valve breakage in shunt systems of children with posthemorrhagic hydrocephalus after minor head trauma-a case series. Childs Nerv Syst 36:2027-2031, 2020

11. Shimizu S, Utsuki S, Suzuki S, Oka H, Fujii K: Obstruction of a Codman-Hakim programmable valve by a migrating pressure control cam. J Neurosurg 103:270-271, 2005

12. Stone JJ, Walker CT, Jacobson M, Phillips V, Silberstein HJ: Revision rate of pediatric ventriculoperitoneal shunts after 15 years. J Neurosurg Pediatr 11:15-19, 2013 